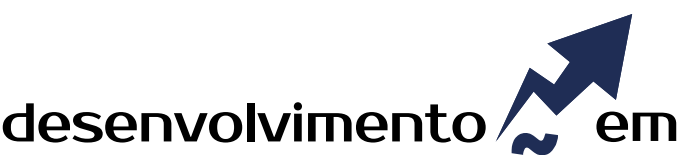 QUESTÂO
}

\section{Feiras Colaborativas e Economia Criativa em Caruaru, Pernambuco}

http://dx.doi.org/10.21527/2237-6453.2020.52.286-307

Recebido em: $14 / 6 / 2019$

Aceito em: 20/5/2020

Elisabeth Cavalcante dos Santos, ${ }^{1}$ Camila de Melo Silva ${ }^{2}$

\begin{abstract}
RESUMO
Este trabalho tem como objetivo analisar as feiras colaborativas que constituem a Economia Criativa da cidade de Caruaru-PE. Para isso buscou-se identificar o perfil dos seus empreendimentos e empreendedores(as) e compreender como ocorrem os processos de produção, circulação e consumo. Foi adotada abordagem qualitativa, e a pesquisa caracteriza-se como descritiva. Foram realizadas visitas a cinco feiras colaborativas e oito entrevistas abertas e semiestruturadas com produtores(as) locais que participam das feiras estudadas. Como resultados, constatou-se que as feiras colaborativas têm valorizado marcas autorais locais e gerado oportunidades para produtores iniciantes exporem, divulgarem e venderem seus produtos, bem como realizarem parcerias. Verificou-se também que a maioria dos empreendedores que participam das feiras são mulheres, e que estas sentem diferenças em relação às feiras colaborativas independentes e aquelas promovidas por órgãos públicos, como a prefeitura da cidade. Ressaltou-se a importância dessas feiras na inserção profissional de jovens recém-formados, que possuem empreendimentos com forte posicionamento social e ambiental, o que os diferencia dos negócios locais. Por fim, dois pontos foram destacados: a importância de se compreender a dinâmica da economia criativa a partir do contexto na qual ela se insere e que a atuação em feiras aparece como alternativa à situação desemprego, por meio da inserção num mercado informal, atrelada a uma situação de vulnerabilidade dos agentes entrevistados.
\end{abstract}

Palavras-chave: Economia da cultura. Economia criativa. Feiras colaborativas.

\section{COLLABORATIVE FAIRS AND CREATIVE ECONOMY IN CARUARU, PERNAMBUCO}

\begin{abstract}
This work aims to analyze the collaborative fairs that constitute the Creative Economy of the city of Caruaru-PE. To do this, sought to identify the profile of their enterprises and entrepreneurs, and understand how the processes of production, circulation and consumption occur. A qualitative approach was adopted, and the research is characterized as descriptive. Visits were made to 5 collaborative fairs, and 8 opens and semi-structured interviews with local producers who participate in the studied fairs. As a result, it was found that collaborative fairs have valued local copyright brands and created opportunities for beginning producers to exhibit, advertise and sell their products, as well as to establish partnerships. It was also found that the vast majority of entrepreneurs who participate in the fairs are women, and that they feel differences in relation to independent collaborative fairs, and those promoted by public bodies, such as the city hall. It was emphasized the importance of these fairs in the professional insertion of young graduates, who have enterprises with a strong social and environmental position, which differentiates them from local businesses. Finally, two points were highlighted: the importance of understanding the dynamics of the creative economy from the context in which it is inserted; and that the performance in fairs appears as an alternative to the unemployment situation, through an insertion in an informal market, linked to a situation of vulnerability of the agents interviewed.
\end{abstract}

Keywords: Culture economy. Creative economy. Collaborative fairs.

\footnotetext{
${ }_{1}^{1}$ Doutora em Administração pela Universidade Federal da Paraíba (UFPB). Professora da Universidade Federal de Pernambuco (UFPE), Centro Acadêmico do Agreste (CAA. http://lattes.cnpq.br/4908041021886939. https://orcid.org/0000-0003-3133-7290. elisabeth.csantos@ufpe.br

${ }^{2}$ Graduada em Administração pela Universidade Federal de Pernambuco (UFPE), Centro Acadêmico do Agreste (CAA). http://lattes.cnpq.br/7270725023920512. https://orcid.org/0000-0001-9208-5619. kamillamellosilva.cm@gmail.com
} 
O conceito de Economia Criativa surge no contexto europeu da década de 90, a partir da noção de "indústrias culturais", que englobam atividades relacionadas à indústria cultural e às artes, juntamente a atividades anteriormente não relacionadas à ideia de criatividade, como desenvolvimento de softwares, games, etc. (VIVANT, 2013). Para Florida (2002), é uma economia que cresce por meio da capacidade que possui de atrair uma classe criativa, que se caracteriza por ser diversa e bem qualificada, e que é capaz de criar novas ideias, novos modelos de negócios e desenvolvimento regional.

Para Vivant (2013), a Economia Criativa refere-se ainda a estratégias de desenvolvimento econômico, comprometidas pela lógica industrial. Para além dessa lógica industrial, entretanto, observa-se na Economia Criativa a existência de distintos segmentos, com diferentes demandas, como aqueles ligados às produções artísticas. Afinal, entendida sob uma perspectiva ampla, essa economia corresponde a um "ciclo que engloba a criação, produção e distribuição de produtos e serviços que usam a criatividade, o ativo intelectual e o conhecimento como principais recursos produtivos" (CAIADO, 2008, p. 3).

Em termos quantitativos e econômicos, a Economia Criativa mostra-se relevante, por exemplo, por ter sido a área menos impactada diante do cenário econômico adverso do período 2013-2015, quando comparada à totalidade da economia nacional, de acordo com dados da Firjan (2016). A participação do PIB Criativo no PIB brasileiro cresceu de 2,56\% para 2,64\%, mantendo a tendência observada desde meados da década passada. Como resultado, a área criativa foi responsável por gerar uma riqueza de $\mathrm{R} \$$ 155,6 bilhões para a economia brasileira no ano de 2015, valor equivalente à soma dos valores de mercado das marcas Facebook, Zara e L'Oréal reunidas (FIRJAN, 2016).

Em Pernambuco, de acordo com dados de 2017 da Relação Anual de Informações Sociais (RAIS, 2019), observa-se um total de 41.182 microempreendedores individuais, 10.629 estabelecimentos formais, 51.811 empresários e 132.956 pessoas ocupadas formalmente na Economia Criativa. Na cidade de Caruaru-PE, local onde se desenvolveu a pesquisa, essa Economia é formada por 1.751 microempreendedores individuais, 672 estabelecimentos formais, 2.423 empresários e 5.969 pessoas ocupadas formalmente. Tais números são relevantes para uma cidade de estimadamente 356.872 habitantes em 2018, de acordo com o Instituto Brasileiro de Geografia e Estatística (IBGE), inserida numa região marcada por forte índice de informalidade (ALMEIDA PEREIRA, 2018).

Neste trabalho, entende-se que as feiras colaborativas estimulam o desenvolvimento de da Economia Criativa local. No município de Caruaru-PE, situado no Agreste de Pernambuco, historicamente marcado pela cultura do comércio, informalidade, pela produção ligada à confecção, e também pela cultura do artesanato feito em barro e do pífano (SANTOS; HELAL, 2017, 2018; SÁ, 2018a, 2018b), observa-se, nos últimos anos, o crescimento dessas feiras colaborativas, protagonizadas por profissionais de diferentes áreas, que encontram ali uma forma de inserir suas pequenas produções no mercado.

Diante desse contexto, este trabalho buscou analisar as feiras colaborativas que constituem a Economia Criativa da cidade de Caruaru-PE. Para tanto, buscou-se identificar o perfil dos empreendimentos e empreendedores que atuam nessas feiras, e compreender como ocorrem os processos de produção, circulação e consumo dos produtos comercializados. Acredita-se que novos formatos de organizações e de trabalho têm surgido e se desenvolvido nos últimos anos diante de uma maior dificuldade de inserção no mercado de trabalho formal, associada ao crescimento da chamada econo- 
mia criativa, principalmente nos contextos tidos como periféricos. Daí a necessidade de entender essa "nova" economia, e as formas de trabalho que a ela estão associadas, a partir de uma análise crítica.

\section{APOIO TEÓRICO}

\section{Economia Criativa}

Nesta seção, parte-se do pressuposto de que o conceito de Economia Criativa, que ganha força nos anos 90, deriva de uma discussão anterior, que diz respeito à Economia da Cultura, que começa a ganhar força no pós-Segunda Guerra, sendo reconhecida nos anos 70 (TOLILA, 2007). Essa economia tem como base o entendimento da cultura como um "recurso", que pode ser utilizada para diversas finalidades, entre elas o desenvolvimento econômico, promoção de cidadania e lutas por justiça e igualdade social.

Nessa lógica, a cultura passa a ser vista como dotada de utilidades práticas, o que faz com que as instituições comecem a compreendê-la como alvo de investimento e como qualquer outro recurso que pode trazer algum retorno, seja incentivos fiscais, comercialização, conversão de uma atividade não comercial em comercial, etc. O importante é que haja algum resultado, "por exemplo, na saúde, na educação, na formação de capital social ou no apoio e reforço da sociedade civil" (YÚDICE, 2006, p. 33).

Cabe reforçar aqui que a visão da cultura como um recurso, destacada neste artigo, é um modo muito particular de pensar a cultura, priorizando o seu lado tangível, material que pode ser produzido, comercializado, consumido e, consequentemente, ter retorno econômico mensurável. Entende-se, porém, que a cultura não se limita a essa visão, mostrando-se também imaterial e simbólica, expressando a autenticidade de um povo, seus valores, seus modos de ser, de ver e compreender o mundo e a história.

Os modelos de negócio criados a partir da economia da cultura, que priorizam a inovação e uso da criatividade, são as formas que os empreendimentos adquirem ao arranjar, de modo particular, os componentes de uma ou mais cadeias produtivas responsáveis pelo ciclo de um tipo de produto. Eles unem produção, distribuição e consumo, e balanceiam os interesses dos consumidores e dos integrantes do próprio negócio. Para analisar os modelos de negócio cultural é necessário diferenciar os níveis de produção, de distribuição e de consumo, de acordo com Doria (2007).

O nível da produção envolve as relações necessárias para a produção de um determinado bem cultural, sejam elas relações industriais, comerciais, de intermediação, pessoais com artistas, contratos com fornecedores ou compradores, royalties cabíveis, etc. O nível da distribuição, por sua vez, envolve a disseminação do produto no mercado, podendo ser meios físicos ou eletrônicos, abrangendo os elos da cadeia logística, as relações comerciais determinantes e as formas de venda correspondentes (pagamento à vista, a prazo, consignação, etc.). Já o nível do consumo refere-se ao mercado formado por aqueles a quem os bens se destinam, sejam empresas consumidoras, atacadistas ou varejistas, e os consumidores finais aos quais se direcionam as ações de marketing, quando cabíveis (DORIA, 2007). 
O conceito de Economia Criativa, de acordo com Reis (2008), surgiu na Austrália em 1994, inspirado pelo projeto Creative Nation. Entre outros elementos, tal projeto defendia a importância do trabalho criativo, sua contribuição para a economia do país e o papel das tecnologias como aliadas das políticas culturais (REIS, 2008). Nesse sentido, a Economia Criativa surge como uma estratégia para estimular o mercado, ampliando os horizontes de possibilidade por meio de mudanças impulsionadas pela criatividade.

Apesar dessa compreensão sobre o surgimento da Economia Criativa, existem prenúncios desse entendimento desenvolvidos na obra de Celso Furtado, economista brasileiro, desde a década de 70, quando o autor acusava o imperialismo velado que mantinha o Brasil em situação econômica de dependência (PACHECO; BENINI, 2018). A criatividade seria o mote da teoria de desenvolvimento econômico do economista, que acreditava ser possível combater as desigualdades existentes no contexto brasileiro, decorrentes das estruturas de concentração de poder (PACHECO; BENINI, 2018).

Ademais, na literatura sobre Economia Criativa, a criatividade aparece como uma importante ferramenta para a criação de cidades menos desiguais, mais sustentáveis, mais flexíveis para lidar com as adversidades, culturalmente diversas, e com maiores possibilidades de comunicação e compartilhamento entre as pessoas (LANDRY, 2008). John Howkins denomina essas cidades criativas de ecologias criativas, e frisa que, nesses locais - caracterizados por ampla circulação de pessoas diferentes, mercados ativos, ambientes estruturalmente adequados, e maiores redes de banda larga - "o aprendizado é mais rápido, a colaboração é mais fácil e a novidade é mais estimulante" (HOWKINS, 2011, p. 126).

De modo geral, Economia Criativa é entendida como um

ciclo que engloba a criação, produção e distribuição de produtos e serviços que usam a criatividade, o ativo intelectual e o conhecimento como principais recursos produtivos. São atividades econômicas que partem da combinação de criatividade com técnicas e/ou tecnologias, agregando valor ao ativo intelectual. Ela associa o talento a objetivos econômicos. É, ao mesmo tempo, ativo cultural e produto ou serviço comercializável e incorpora elementos tangíveis e intangíveis dotados de valor simbólico (CAIADO, 2008, p. 3).

Desse modo, percebe-se que, diferentemente da economia tradicional, de manufatura, agricultura e comércio, a Economia Criativa, basicamente, foca no potencial individual ou coletivo para produzir bens e serviços criativos.

De acordo com as Nações Unidas (2012), as atividades do setor estão baseadas no conhecimento e produzem bens tangíveis e intangíveis, intelectuais e artísticos, com conteúdo criativo e valor econômico. Além disso, essa Economia seria movida por uma classe criativa, formada por trabalhadores altamente qualificados, que desenvolvem uma ampla variedade de trabalhos, atuando em segmentos diversos e bem remunerados, e que compartilham de um mesmo ethos, que valoriza a criatividade, a individualidade, a diferença e o mérito (FLORIDA, 2002).

De acordo com as informações expostas, aparentemente a Economia Criativa é muito semelhante ao que diz a literatura sobre Economia da Cultura. Percebemos, entretanto, as diferenças entre as duas, quando entendemos o escopo de cada uma delas. Miguez (2007) comenta que existe dentro do campo de estudos da cultura a tendência 
a se considerar a Economia Criativa como ampliação do campo da Economia da Cultura, da mesma forma que a Economia da Cultura pode ser vista como uma ampliação do campo da Economia da Arte - até porque, no conjunto, a Economia Criativa reúne setores, práticas e dinâmicas socioeconômicas que, a rigor, não são estranhas ao campo da Economia da Cultura.

Para Sanguinet, Calvete e Waismann (2016), "a Economia Criativa é composta por uma gama de setores superior à da Economia da Cultura, o que torna a primeira mais abrangente e diversificada" (p. 284), tendo em vista que envolve áreas como tecnologia, design, entre outras. Percebe-se que o debate sobre o que está sendo chamado de Economia Criativa não surgiu do zero. Segundo Miguez (2007, p. 98), muito ao contrário, beneficia-se "do importante e indispensável repertório de reflexões que, ao longo dos últimos cinquenta anos, deram corpo ao que chamamos de Economia da Cultura".

Importante destacar que a Economia Criativa ganha destaque num momento de reestruturação produtiva, na qual muitas pessoas veem a necessidade de recorre aos chamados trabalhos autônomos que, como afirma Valiatti (2017), são, basicamente os profissionais em ocupações criativas (consultores, designers, artesãos, etc.). Nesse sentido, Sanguinet, Calvete e Waismann (2016, p. 284-285) apontam para uma reflexão fundamental:

A Economia Criativa põe em primeiro plano uma análise economicista de curto prazo na mensuração das atividades e seu efeito multiplicador para a geração de emprego, renda, arrecadação de impostos, valor agregado, etc., que é tão caro aos economistas. Assim, ficam relegadas a um segundo plano as discussões que são centrais nas atividades culturais: identidade, emancipação, autonomia e desenvolvimento social e territorial.

Além disso, os autores destacam o expressivo percentual de trabalhadores informais no setor, principalmente na área de cultura, devido ao alto número de fechamentos de postos de trabalhos formais, bem como baixa contribuição previdenciária, o que leva à situação de insegurança dos trabalhadores da cultura, que compõem a chamada Economia Criativa, "tendo em vista que não poderão usufruir de direitos trabalhistas como aposentadoria, pensão ou licenças como saúde, acidente do trabalho, maternidade, etc." (SANGUINET; CALVETE; WAISMANN, 2016, p. 294).

Nesse sentido Vivant (2013), em pesquisa sobre as condições dos trabalhadores criativos, lança crítica à noção de cidades criativas, mostrando suas contradições. A autora aponta para a existência de forte precarização dos trabalhadores, destacando dificuldades que estes agentes vivenciam no que se refere ao acesso a locais de trabalho, de comércio e até mesmo residenciais. Desse modo, a autora combate a aplicação de "um brilho criativo a estratégias neoliberais", como a flexibilização do trabalho, chamando a atenção para "a criatividade como uma alternativa frente à precariedade" (VIVANT, 2013, p. 62, tradução nossa).

Em relação aos diferentes segmentos que compõem essa Economia Criativa, o primeiro mapeamento foi realizado em 1998 no Reino Unido. Este mapeamento mostrou que a Economia Criativa representava $8 \%$ da atividade econômica total e empregou entre $7 \%$ e $8 \%$ da população ativa, na época. Para as definições dos setores criativos foram consideradas "aquelas atividades que têm origem na criatividade, habilidade e talento individual, e que potencializam a geração de riqueza e empregos através da geração e 
exploração da propriedade intelectual" (NEWBIGIN, 2010, p. 21). Nesse exercício foram identificados 13 setores de maior potencial, as chamadas atividades criativas. Este estudo foi realizado pelo Departamento de Cultura, Mídia e Esporte (DCMS), e os 13 setores identificados foram: Artesanato, Arquitetura, Artes Cênicas, Artes e Antiguidades, Cinema, Design, Editorial, Moda, Música, Publicidade, Software, Software Interativo de Lazer (video games) e Televisão e Rádio.

"Os setores criativos são aqueles cujas atividades produtivas têm como processo principal um ato criativo gerador de um produto, bem ou serviço, cuja dimensão simbólica é determinante do seu valor, resultando em produção de riqueza cultural, econômica e social" (MINISTÉRIO..., 2011, p. 22). De acordo com a Conferência das Nações Unidas sobre Comércio e Desenvolvimento (UNCTAD) para a Economia Criativa, são quatro as áreas criativas e nove os setores criativos: área de Patrimônio, que compreende os sítios culturais (sítios arqueológicos, museus, bibliotecas, exposições, etc.) e as expressões culturais tradicionais (artesanato, festivais, celebrações); a área de Artes, que inclui as artes visuais (pinturas, esculturas, fotografia e antiguidades), e artes cênicas (música ao vivo, teatro, dança, ópera, circo, teatro de fantoches, etc.); a área de Mídias, que abrange dois setores: as editoras e mídias impressas (livros, imprensa e outras publicações) e audiovisuais (filmes, televisão, rádio e demais radiodifusões) e, por fim, a área de Criações Funcionais, que se dividem em Design (interiores, gráfico, moda, joalheria, brinquedos), em Novas Mídias (arquitetônico, publicidade, cultural e recreativo, pesquisa e desenvolvimento (P\&D) criativo, outros serviços criativos digitais), e Serviços Criativos: arquitetônico, publicidade, cultural e recreativo, Pesquisa e Desenvolvimento (P\&D) criativo, outros serviços criativos digitais (NAÇÕES UNIDAS, 2012).

\section{Feiras}

As feiras livres ou feiras populares surgiram no século 9으, na Europa, quando começaram a organizar espaços com o objetivo de suprir a população local. No Brasil tiveram origem ibérica, trazidas de Portugal, no período da colonização (ALMEIDA, 2009).

Conforme Mascarenhas e Dolzani (2008, p. 75), a feira livre tradicionalmente "constitui modalidade de mercado varejista ao ar livre, de periodicidade semanal, organizada como serviço de utilidade pública pela municipalidade e voltada para a distribuição local de gêneros alimentícios e produtos básicos". Assim entendido, o conceito tradicional de feira livre remete à venda de produtos alimentícios e básicos.

Além disso, as feiras são territórios por vezes formatados pelos setores hegemônicos para a comercialização da mercadoria, mas que por aglomerar multidões, acabam resultando em expressivos espaços de sociabilidade. Essa sociabilidade acaba tornando-se alternativa ao projeto dominante, por se desenvolver marginalmente, "nos interstícios dos territórios 'econômicos'" (MASCARENHAS; DOLZANI, 2008, p. 75).

Como espaços de sociabilidade, as feiras passaram a oferecer mais alternativas para os visitantes além da tradicional oferta de suprimentos, disponibilizando também cultura e arte, criando forte vínculo com a cultura e identidade locais (MASCARENHAS; DOLZANI, 2008), como acontece na cidade de Caruaru, cuja feira é reconhecida como patrimônio cultural imaterial brasileiro, pelo Instituto do Patrimônio Histórico e Artístico Nacional (IPHAN): 
[...] A Feira se firmou como um lugar de socialização, de permanente construção de identidades e de exposição da sabedoria e criatividade populares. A Feira de Caruaru, na verdade, são muitas feiras que compõem um lugar de referência viva da história do agreste pernambucano. Sintetizando a riqueza cultural do Nordeste, o maior centro de comércio popular do interior da região conta com 30 mil feirantes.

A Feira de Caruaru é também lugar de cultura, de memória e de continuidade de saberes, fazeres, produtos e expressões artísticas tradicionais - que continuam vivos no comércio de gado e dos produtos de couro, nos brinquedos reciclados, nas figuras de barro do Mestre Vitalino, nas redes de tear, nos utensílios de flandres, no cordel, nos poetas e repentistas, nas bandas de pífanos, nas gomas e farinhas de mandioca, nas flores, ervas e raízes medicinais (IPHAN, 2006, p. 15).

Nessa cidade percebe-se uma feira criada de forma desordenada, para escoar a produção dos(as) pequenos(as) produtores(as) locais, que atuam muitas vezes em fabricos e facções, no caso das confecções (PEREIRA, 2011), e em ateliês, muitas vezes no próprio lar, caracterizando as "oficinas-casas-ateliês", no caso do artesanato (SÁ, 2018b). Dada a localização geográfica favorável da cidade, que está situada entre dois importantes eixos rodoviários, "que se cruzam leste/oeste, pela BR 232 e norte/sul pela BR 104" (LIRA, 2011, p. 110), 3 a feira tomou grandes proporções. Após tomar várias ruas do centro da cidade, na década de 80 foi realizada a transferência da feira para o parque 18 de Maio, ficando os produtos organizados por setores conforme suas características (LIRA, 2011, p. 115).

Atualmente Caruaru conta com diversas feiras: a feira do artesanato, a feira do gado, a feira do Paraguai ou de importados, a feira da sulanca, a feira livre, que é subdividida em setores como frutas e verduras, raízes e ervas medicinais, troca-troca, flores e plantas ornamentais, couro, confecções populares, bolos, goma e doces, ferragens, artigos de cama, mesa e banho, fumo, produtos importados, mercado de farinha, mercado de carnes (IPHAN, 2006). Nessa cidade, a feira está tão presente na vida e história dos seus habitantes, que Sá (2018a) identifica um verdadeiro habitus feirante, ou seja, um verdadeiro jeito de ser feirante (que envolve saberes-fazeres relativos a negociar $\mathrm{e}$ vender produtos, gerenciar recursos, etc.), que rege práticas e relações sociais estabelecidas na cidade.

Para Erig e Melo (2015), as feiras são meios de sobrevivência e indicam que além dos aspectos econômicos, há um protagonismo dos aspectos culturais e simbólicos no plano das representações dos consumidores, não significando somente um sistema local de comercialização. Desse modo, as feiras livres, para além da simples comercialização, compra e venda de mercadoria, podem ser pensadas também como espaços não formais de aprendizagem, que revelam a dimensão educativa das cidades e da relação do trabalho com a formação humana (SOUZA, 2015).

\footnotetext{
3 "São espaços de produção dentro das residências espalhadas pela cidade, que atuam sob condições insalubres" (PEREIRA, 2011, p. 113). "Caracterizadas como um tipo de unidade produtiva prestadora de serviços especializados em uma etapa ou tarefa da confecção de determinada peça de roupa, que de modo subcontratado, 'terceirizado informalmente', conecta-se aos fabricos" (PEREIRA, 2011, p. 113).
} 
A feira abriga diferentes motivações, variados nichos de mercado, o que faz com que as pessoas se sintam parte dessa cultura, desse espaço criado em razão delas. As motivações são diversas: a alimentação típica, o artesanato local, as apresentações artísticas, produtos importados, atividades lúdicas, simplesmente lazer, a feira sempre atrai as pessoas (ERIG; MELO, 2015).

Neste trabalho buscamos entender as feiras colaborativas na cidade de Caruaru que, diferente da feira tradicional dessa cidade, não acontece semanalmente, tendo periodicidade flexível, além de serem realizadas por profissionais ligados aos segmentos criativos anteriormente apresentados. Essas feiras colaborativas auxiliam o(a) pequeno(a) produtor(a) a expor e vender seus produtos em um espaço organizado e compartilhado, que geralmente é público, e se apresentam como um modelo de exposição e venda de produções independentes, ligadas aos diferentes setores criativos.

As feiras estudadas neste trabalho caracterizam-se por serem eventualmente criadas para unir diferentes marcas e públicos locais. São compostas por segmentos como artes, moda, gastronomia, artesanato, entre outros, o que permite que os(as) visitantes e consumidores(as) dessas feiras tenham uma ampla variedade de produtos e preços. O seu principal objetivo é promover o(a) empreendedor(a) local, valorizar o produtor(a) independente, promover a troca de ideias, experiências e cooperação.

\section{PROCEDIMENTOS METODOLÓGICOS}

A presente pesquisa é de abordagem qualitativa e caracteriza-se como descritiva (BARROS; SOUZA, 2007; FLICK, 2009; GERHARDT; SILVEIRA 2009; GIL, 2016). A coleta de dados foi feita mediante entrevistas abertas e semiestruturadas (TRIVIÑOS, 1987; GIL, 2016), pela necessidade de apreender significados atribuídos pelos(as) entrevista$\operatorname{dos}($ as).

Ao todo foram realizadas oito entrevistas abertas com produtores(as), de oito diferentes marcas, que participam das feiras colaborativas na cidade de Caruaru-PE. As entrevistas foram feitas no período de 8 a 22 de novembro de 2017, tiveram duração de 16 a 39 minutos, foram gravadas em áudios e transcritas posteriormente pelas autoras deste trabalho. $O$ roteiro das entrevistas continha 25 questões e buscou entender o perfil dos(as) empreendedores(as) atuantes nas feiras colaborativas, como se dá a produção, distribuição e consumo dos seus produtos, o significado que atribuem ao seu empreendimento/marca, a caracterização e o entendimento que possuem sobre as feiras colaborativas, o entendimento que possuem sobre economia criativa e sua concepção sobre como as feiras colaborativas e a Economia Criativa poderiam contribuir para o desenvolvimento de Caruaru-PE.

A seleção dos(as) entrevistados(as) ocorreu por meio de participação das pesquisadoras como visitantes das feiras. Após conhecer as marcas que atuavam nas feiras visitadas, foi realizado contato por meio das redes sociais Instagram e WhatsApp, e solicitada a participação na pesquisa. Desse modo, foram marcadas entrevistas com os(as) produtores(as) que tinham disponibilidade, nos locais indicados pelos(as) entrevistados(as). As feiras colaborativas visitadas foram Mercado Criativo, Estação da Paixão, Semana Integra UFPE, Ecoar e Feira Cria, e o conhecimento delas ocorreu por meio das redes sociais Instagram e Facebook. 
O Mercado Criativo foi um evento organizado pela Fundação de Cultura e Turismo da prefeitura de Caruaru, que aconteceu nos dias 13, 14 e 15 de abril de 2017, na Rua Silvino Macedo, mais conhecida como a Rua da Má Fama. Foi uma feira composta por mais de 20 marcas na área de Economia Criativa da cidade, dos mais variados segmentos, entre eles moda, arte, decoração e gastronomia. As marcas que participaram do Mercado Criativo pagaram uma taxa à prefeitura para manutenção e estrutura do evento. A visita à feira aconteceu num sábado, no dia 15 de abril, no período da tarde.

A Estação da Paixão foi um evento coletivo organizado por artistas na antiga Estação Ferroviária de Caruaru, e ocorreu nos dias 14 e 15 de abril de 2017, período da Semana Santa comemorada na cidade. Nesse evento, além da feira colaborativa, que começava a partir das 16 horas, também aconteceram apresentações artísticas de músicos, declamação de poesia, gastronomia, entre outros. A feira colaborativa foi visitada no dia 15 de abril no período da tarde.

A Semana Integra UFPE/CAA é um evento de extensão promovido pela Coordenação de Extensão da universidade com participação de alunos, professores, técnicos, entre outros, com o objetivo de mostrar ao estudante novato um pouco do que acontece na UFPE. É um evento que promove palestra, exposição, apresentação artística, oficinas e a feira colaborativa. A 2a feira do Integra CAA aconteceu nos dias 9 e 10 de agosto, no período da noite. Para poder participar os(as) empreendedores(as) tinham de enviar um e-mail informando nome dos participantes e descrição dos produtos que iriam vender. A visita aconteceu na quarta-feira, dia 9 de agosto no período da noite. Pôde-se observar produtos decorativos, roupas, bijuterias, entre outros.

A Feira Ecoar aconteceu dia 19 de agosto, na antiga Estação Ferroviária da cidade de Caruaru-PE. Organizada por alunos da Universidade Federal de Pernambuco, a Ecoar é uma feira cultural, que tinha como temática "arte, sustentabilidade e causas sociais com o propósito de transformar o meio em que vivemos". Durante o evento ocorreu a feira colaborativa, cineclube, rodas de diálogos e intervenções culturais. A visita à feira foi no dia 19 de agosto de 2017, no período da tarde. Nesse horário foram realizadas a feira colaborativa e rodas de diálogos. As demais manifestações aconteceram no período da noite.

A Feira Cria foi um evento criado pelo Diretório Acadêmico de Design da Universidade Federal de Pernambuco-CAA, que tinha como objetivo apresentar à comunidade universitária as produções de estudantes do curso de Design. A feira aconteceu no dia 8 de novembro de 2017, na quadra esportiva da UFPE-CAA. Além da feira colaborativa foram realizadas oficinas, apresentações musicais e palestras. O conhecimento da feira deu-se por intermédio da rede social Instagram.

Para a análise das informações coletadas, foi utilizada a análise temática de conteúdo, que constitui importante etapa da análise de conteúdo proposta por Bardin (2011), na qual se descobrem "núcleos de sentido que compõem a comunicação e cuja presença, ou frequência de aparição, podem significar alguma coisa para o objetivo analítico escolhido" (p. 135). Assim, as informações coletadas foram transcritas literalmente e organizadas em categorias que atendem aos objetivos do trabalho, a saber: perfil dos entrevistados (sua idade, gênero, escolaridade, ocupação e sua principal fonte 
de renda); características do empreendimento, do produto, da produção, distribuição e consumo; caracterização das feiras colaborativas de acordo com os(as) empreendedores(as) entrevistados(as) e entendimentos sobre Economia Criativa.

\section{APRESENTAÇÃO E ANÁLISE DOS RESULTADOS}

Nesta seção são caracterizados o perfil dos empreendimentos e empreendedores(as), a produção, distribuição, consumo e as feiras colaborativas.

\section{Perfil dos empreendimentos e empreendedores(as) que fazem as feiras colaborativas}

Nesta seção, parte-se do pressuposto de que, para compreender o fenômeno das feiras colaborativas, é importante compreender os diferentes empreendimentos envolvidos, bem como o perfil dos(as) empreendedores(as) que nelas atuam. Por meio dessa pesquisa percebe-se que esses(as) empreendedores(as) são produtores(as) independentes, que buscam oferecer produtos ou serviços ligados aos setores criativos, e que geralmente possuem posicionamento e mensagem social clara.

As entrevistadas 1 e 7 são responsáveis por dois empreendimentos de acessórios e bijuterias. Seus produtos são brincos, pulseiras, colares, anéis, e buscam atender prioritariamente ao público feminino, embora a marca da entrevistada 7 também produza para o público masculino e infantil. Apesar de serem do mesmo segmento, suas marcas carregam posicionamentos e mensagens diferentes. A entrevistada 1, por exemplo, preza pela sustentabilidade, uma vez que utiliza materiais recicláveis, como papelão, tecido, papel e cordão na produção dos acessórios. Já a entrevistada 7 enfatiza a "liberdade, delicadeza, personalidade e transformação" da mulher na sua marca.

Os empreendimentos das entrevistadas 4 e 5 são voltados para produção de roupas. A marca da entrevistada 5 é de vestuário para o público feminino, e seus produtos são cropped, vestidos, saias midi, pantacourt e quimonos. Sua marca procura trazer referências do universo afro-brasileiro, valorizando a cultura afro. Já a marca da entrevistada 4 é idealizada por uma estudante do curso de Comunicação Social na Universidade Federal de Pernambuco, que busca atender tanto ao público feminino quanto ao masculino com peças unissex. Seus produtos são calças, camisas, saias e vestidos. De acordo com a entrevistada 4, sua marca busca representar o agreste de Pernambuco, trazendo um "novo estilo, baseado na versatilidade e no conforto [...]".

O empreendimento da entrevistada 3 é formado por quatro estudantes do curso de Design na Universidade Federal de Pernambuco que ainda não conseguem viver totalmente da sua marca, destacando-se que os auxílios estudantis concedidos pela universidade são sua principal fonte de renda. $O$ empreendimento é um ateliê de experimento no qual elas confeccionam diversos produtos, por exemplo, roupas, adesivos, ímãs de geladeira, flâmulas, quadrinhos, acessórios de modas, carteiras e cartucheiras, bolsas e nécessaires. A marca trabalha a mensagem do empoderamento feminino.

A marca da entrevistada 2 também foi idealizada por estudantes de Design na Universidade Federal de Pernambuco. Seus produtos são chaveiros, máscaras de dormir e almofadas. A marca representa o público Geek e nerd por meio de mimos decorativos feitos de feltro. 
A marca da entrevistada 6 é um estúdio de Design formado por três mulheres, todas formadas em Design pela Universidade Federal de Pernambuco. Atualmente o estúdio desenvolve projetos de identidade visual e peças de comunicação visual, e também possui uma linha de papelaria personalizada. Seus produtos são pacotes de criação de marcas, incluindo material de divulgação (como cartões de visitas, fôlderes, catálogos, etc.), cadernos, agendas e planejadores. As empreendedoras também são idealizadoras de um evento anual que tem como objetivo unir e fortalecer as mulheres empreendedoras de Caruaru e região. Além da feira colaborativa, o evento conta com rodas de diálogos sobre o empreendedorismo e empoderamento feminino.

O entrevistado 8 é o idealizador de empreendimento que surgiu da necessidade de reaproveitar a madeira que sobrava do trabalho que fazia com seu pai. Seus produtos são de decoração e design de interiores, como vasos de plantas, luminárias, porta-lápis e lustre, tudo confeccionado com madeira reaproveitada. Sua marca trabalha com a mensagem de sustentabilidade e consumo consciente.

Diante do que foi apresentado sobre os empreendimentos e marcas, percebe-se que boa parte deles possui posicionamento social claro, veiculando mensagens associadas à sustentabilidade e empoderamento feminino. $O$ fato de produzirem peças em pequenas escalas e localmente contribui para a sustentabilidade do negócio. Sobre as(os) empreendedoras(es) participantes das feiras colaborativas, constata-se que boa parte delas(es) são jovens e mulheres. Além das sete entrevistadas, nas feiras visitadas pôde-se observar também uma grande participação das mulheres expondo produtos. A idade das pessoas entrevistadas que participam dessas feiras colaborativas está entre 19 e 33 anos, e em sua maioria são estudantes universitárias. Duas das entrevistadas já possuem curso superior completo e apenas um dos entrevistados só tem o Ensino Médio.

Quando questionados na entrevista qual era a sua principal fonte de renda, somente três entrevistadas ainda não conseguem se manter com sua empresa, os demais empreendedores têm suas marcas como sua principal fonte de renda. O empreendimento pode, por vezes, ser um complemento de renda, como no caso da entrevistada 3 , que afirma que todas as quatro empreendedoras da marca com a qual trabalha sobrevivem de auxílios estudantis da universidade. Em outros casos, a ajuda dos pais em alguns momentos, ou o trabalho paralelo desenvolvido com eles é essencial, como no caso da entrevistada 5 e do entrevistado 8, respectivamente.

Logo, percebe-se que as pessoas que empreendem nas feiras estudadas buscam se posicionar no mercado, mas não aderindo aos negócios tradicionalmente tidos como locais, como as feiras livres, os fabricos, as facções (LIRA, 2011; SÁ, 2018a; IPHAN, 2006), e sim trazendo novos modelos de negócios, com posicionamentos mais atuais, muitas vezes aprendidos nos cursos universitários. De todo modo, a feira colaborativa ainda se apresenta como meio de sobrevivência (ERIG; MELO, 2015) para essas pessoas, muitas vezes recém-formadas, num momento de reestruturação flexível, levando-as a desenvolverem trabalhos que podem ser caracterizados como autônomos (VALIATTI, 2017).

\section{Produção, Distribuição e Consumo}

De acordo com Doria (2007), o nível da produção envolve todas as relações que se colocam para produzir um determinado bem cultural, sendo evidente a existência de uma diversidade de práticas culturais, processos produtivos e tecnologias utilizadas. Os 
produtos dos microempreendedores estudados estão dentro da área de criações funcionais, que é um dos setores da Economia Criativa, de acordo com a Unctad (NAÇÕES UNIDAS, 2012). Este grupo constitui indústrias mais impulsionadas pela demanda e voltadas à prestação de serviços, com a criação de produtos e serviços que possuam fins funcionais e ainda se divide nos seguintes subgrupos: Design (interiores, gráfico, moda, joalheria, brinquedos) e Novas Mídias (arquitetônico, publicidade, cultural e recreativo, Pesquisa e Desenvolvimento (P\&D) criativo, outros serviços criativos digitais).

Durante as entrevistas realizadas foi possível perceber que as produções são confeccionadas, em sua maioria, totalmente pelas(os) empreendedoras(es), em suas próprias residências, e de forma artesanal, como pode ser constatado nos seguintes relatos:

Minha produção é feita em casa mesmo, tudo é feito por mim, em alguns acessórios tenho ajuda da minha mãe, como te falei minha mãe faz a parte do crochê, porque eu não sei bordar, não sei costurar essa parte de crochê. Então a parte de acessórios sustentáveis e papelão e retalhos de tecido, no outro eu utilizo linhas também... E os de aço que faço, tipo arame, eu utilizo arame de cerca elétrica, o meu padrasto conseguiu com os amigos dele muito arame de cerca elétrica, daí eu tive a ideia de utilizar para não ter que comprar arame. O máximo que eu faço para não ter que comprar. Alguns acessórios que eu tenho em casa que não utilizo eu desmancho e utilizo as pecinhas, as pedrinhas, em outras peças ganho de outras pessoas também, é por aí (Entrevistada 1).

Nas nossas casas. A gente pretende montar um ateliê até porque a logística fica difícil porque vê, a gente tem uma peça que precisa passar pela mão de todas nós, então a gente tem que sair na casa de uma pra deixar a peça, sair da casa de uma, ir para minha casa e depois deixar na casa da outra, assim por diante. Os tecidos que mais utilizamos é o tecido de linho de algodão cru, papel Kraft e outros papéis e um pouco de tinta (Entrevistada 3).

Hoje em dia a gente trabalha totalmente em casa, então eu já tinha a máquina que eu comprei com o primeiro dinheiro que eu ganhei com a venda das roupas do primeiro desfile, aí eu comprei a máquina de costura, foi bem assim que eu cheguei aqui em Caruaru. E hoje em dia a gente já comprou a bancada, o equipamento de corte, o manequim (Entrevistada 5).

Entre as oito marcas entrevistadas, somente duas delas possuem produções fora de suas residências. São as marcas das entrevistadas 6 e 7. A produção de acessórios da marca da entrevistada 7 acontece dentro da sua loja, e é feita pela própria entrevistada que, algumas vezes, solicita a ajuda de amigos(as). Já a produção do empreendimento da entrevistada 6 ocorre em seu estúdio, no prédio da organização que a incubou durante 1 ano. Desse modo, percebe-se que o empreendimento recebeu todo o suporte de um órgão externo para o gerenciamento do seu negócio, e as empreendedoras envolvidas possuem uma divisão clara de tarefas entre elas, apesar de todas se envolverem na produção.

O entrevistado 8 aproveita o espaço de trabalho do pai para produzir suas peças à noite: "Na marcenaria do meu pai eu faço as peças à noite porque durante o dia eu trabalho com o meu pai e à noite eu faço as minhas peças, mas não todos os dias, porque se não a pessoa não vive" (Entrevistado 8). A entrevistada 5 fez o seu ateliê no espaço da garagem que a mãe e a avó utilizam para guardar sobras de materiais. 
A entrevistada 2 menciona o fato de utilizar seu tempo vago em outros ambientes para realizar a produção: “[...] dependendo a gente leva para os cantos para fazer [as peças] esperando o tempo passar, às vezes a gente traz aqui pra faculdade e quando tem uma aula vaga aí costuramos, mas geralmente é em casa mesmo" (Entrevistada 2).

Diante do que foi exposto fica claro que o processo de produção das marcas entrevistadas acontece de modo artesanal e caseiro, como é comum na produção de confeç̧ões na região do agreste de Pernambuco (PEREIRA, 2011, SÁ, 2018a). A autonomia coloca essas(es) empreendedoras(es) no centro de suas atividades diárias, possibilitando a elas(es) um gerenciamento do seu próprio ritmo de trabalho e horários. Essa liberdade e autonomia de horários está ligada à oportunidade de gerir seus próprios negócios, ser patrão de si mesmo, podendo, desta maneira, associar as necessidades do trabalho com as questões pessoais e individuais, como aliar o trabalho com os estudos.

Essa mesma autonomia, entretanto, pode ser caracterizada como uma forma de flexibilização do trabalho, e entendida como uma estratégia neoliberal, de acordo com Vivant (2013). Como consequência, esses agentes criativos se veem numa situação de vulnerabilidade, uma vez que essas(es) empreendedoras(es) não possuem nenhum tipo de vínculo empregatício, pouca ou nenhuma garantia social estabelecida, sendo totalmente responsáveis pelo andamento do negócio, sem ao menos conseguirem sobreviver deles, em alguns casos, e sem uma distinção clara entre tempo de estudo, tempo de trabalho e tempo de lazer, o que reforça a relação feita por Valiatti (2017).

Em termos de distribuição, cabe destacar que as marcas ainda estão em processo de crescimento e expansão, e devido a isso, muitas delas ainda possuem limitações financeiras que não lhes permitem terem estabelecimento fixo para circulação dos seus produtos. Devido a isso, as feiras colaborativas e a Internet tornam-se aliadas na distribuição, pelos baixos custos envolvidos.

Entre os(as) oito entrevistados(as), somente uma empreendedora possui loja física para a distribuição dos seus produtos, a marca da entrevistada 7, que possui duas lojas, uma na cidade de Caruaru-PE e outra em Buíque-PE, além de disponibilizar suas peças na primeira loja colaborativa do agreste pernambucano, localizada em Caruaru, e também via Internet.

Parcerias com blogueiras na divulgação dos produtos também são utilizadas pelos(as) entrevistados(as). Essas parcerias são utilizadas como estratégia de divulgação, porque essas blogueiras são reconhecidas por serem formadoras de opinião. Desse modo, a informação chega ao público consumidor de forma direta, diferenciada e segmentada, por intermédio de pessoas que ao mesmo tempo são consumidoras e também possuem muitos seguidores nas páginas da Internet.

A Internet é o principal meio de distribuição dos produtos das(os) entrevistadas(os). As redes sociais Instagram e Facebook são as mais utilizadas para exposição dos produtos desses empreendedores, e as vendas ocorrem principalmente pelo Instagram. Apenas o empreendimento da entrevistada 6 possui um site com uma loja virtual, na qual se conclui a compra do produto. 
O papel das feiras colaborativas na divulgação dos produtos é mencionado pelas entrevistadas 1, 2, 3 e 5, mas com um alcance menor que a Internet. Esse momento da feira, segundo as entrevistadas, é importante para o cliente ver fisicamente o produto que ele já admirava na Internet. Assim, pode-se afirmar que as feiras possuem um forte papel na divulgação e promoção dessas novas marcas.

A loja colaborativa da cidade também exerce papel importante na divulgação desses produtos, de acordo com as entrevistadas, por ser um espaço físico que reúne várias marcas diferentes. Essa loja foi inaugurada na cidade de Caruaru em 2016, com a proposta de reunir várias marcas locais num mesmo espaço físico. Para terem um espaço nessa loja física, os empreendedores precisam pagar uma taxa correspondente ao tamanho do espaço que alugam. Em troca, eles expõem seus produtos, e a equipe da loja se responsabiliza pela venda e pela geração de relatórios administrativos.

Com relação à entrega dos produtos aos consumidores, quando a venda acontece via Internet, geralmente a processo de entrega se dá via correios, ou por caronas de amigos conhecidos que estão indo em direção à cidade da entrega.

Segundo Doria (2007), as formas de distribuição envolvem a disseminação do produto pelo mercado por todos os meios físicos ou eletrônicos, abrangendo os elos da cadeia logística, as relações comerciais determinantes e as formas de venda correspondentes. Para esses microempreendedores, a Internet é uma grande aliada nas vendas dos produtos e essas novas ferramentas de comunicação social são importantes porque conseguem alcançar muitas pessoas gratuitamente. As feiras e a loja colaborativa são a representação física desses negócios, e além de fugirem dos modelos tradicionais, abrem espaços para novos microempreendedores, para artistas, cooperativas locais ou marcas de pequeno porte para exporem seus trabalhos. Para o consumidor, é uma ótima oportunidade de conhecer novos talentos e ter acessos a artigos exclusivos, valorizando a economia local.

Em termos de consumo, quando questionados sobre quem seriam os seus consumidores, muitas falaram de um "público alternativo", pessoas com consciência de novos conceitos de economia, consumo consciente e apoio local: "Então, são pessoas mais alternativas assim, que prezam pelas coisas diferentes, tipo, as pessoas que consomem meus produtos são pessoas mais conscientes, que têm consciência da importância do apoiar o local, do pequeno empreendedor" (Entrevistada 1). Já a entrevistada 2 afirma: "[...] são esse público geek e gamer, mas a gente percebe que quando a gente vai para as feiras, a gente percebe outras pessoas que acabam comprando. É um público mais alternativo" (Entrevistada 2). As entrevistadas 3, 5, 6 e 7, por sua vez, reforçam o fato de a maioria dos consumidores de seus produtos serem mulheres.

Essa caracterização do público consumidor pelos próprios empreendedores mostra, de certo modo, que esses negócios criativos buscam balancear os interesses dos consumidores e dos integrantes do próprio negócio (DORIA, 2007), considerando que tanto os consumidores quanto os empreendedores são mais conscientes e preocupados com causas sociais e ambientais. Esse resultado também reforça a análise de Locatelli, Benavides e Souza (2014) que, ao analisarem o perfil do consumo em feiras de artesanato em Ilhéus, no Estado da Bahia, perceberam uma ressignificação no consumo, uma 
vez que há uma "procura por produtos diferenciados e simpatia pelo artesanato", passando o consumo "a incorporar um caráter extrapreço, dado pelas características subjetivas dos produtos transacionados nas feiras" (LOCATELLI; BENAVIDES; SOUZA, 2014).

Quando questionadas(os) sobre como eles conseguem identificar esse perfil consumidor, a resposta foi quase unânime: o Instagram é a ferramenta mais utilizada. 0 "novo" perfil consumidor, segundo as entrevistas, mostra que as mulheres exercem protagonismo como consumidoras desses produtos. Além disso, os(as) entrevistados(as) também destacam um perfil de consumidor que consome o que realmente é necessário, se preocupa com a reciclagem e reaproveitamento, com os danos ao planeta, com o coletivo, com a qualidade dos produtos, em vez da quantidade, e em estimular a produção local. Os termos colaborar e compartilhar foram recorrentes nas entrevistas.

\section{As Feiras Colaborativas e a Economia Criativa na Cidade de Caruaru-PE}

Após compreensão das marcas e agentes envolvidos, nesta seção serão analisados os aspectos relacionados às feiras colaborativas que vêm acontecendo na cidade de Caruaru-PE.

Quando os entrevistados foram questionados sobre quando surgiram as feiras colaborativas, muito deles não souberam responder com precisão, ou suas respostas quanto ao surgimento partem do momento em que eles começaram a participar das feiras colaborativas.

Eu fiz um evento aqui em 2015, é, foi em 2015 mesmo que foi o Caco, que foram cinco dias de evento, e nesses dias do evento eu coloquei também uma feirinha colaborativa eu não estou dizendo que foi a primeira, mas que eu já estava observando algumas ascensões de umas feirinhas tipo lá no circo 93 sabe, era um bar que passou por uma reforma que antigamente nos dias de domingo que eles não tinham muito movimento, eles chamavam algumas pessoas que produzem em pequena escala para exporem lá, eu acho que foi por aí que começou esse foco de feirinha colaborativa (Entrevistada 5).

Percebe-se que as feiras colaborativas que têm acontecido recentemente em Caruaru (cidade já conhecida pela feira da sulanca, de artesanato e outras) criam um espaço de socialização e geram novas oportunidades de negócios nos termos da Economia Criativa. Em Caruaru, as feiras colaborativas ocupam espaços e propõem uma nova experiência de compras, fortalecendo o mercado local, valorizando marcas autorais e gerando oportunidades para microempreendedores iniciantes, com pouco capital e sem lojas físicas.

As feiras colaborativas surgem com a proposta de criar espaços para que os(as) empreendedores(as) criativos(as) locais saiam do virtual, apresentem de perto sua produção e ganhem visibilidade. Desse modo, e de acordo com as entrevistas realizadas, elas acabam tornando-se mais um ambiente de divulgação e promoção dos produtos do que propriamente espaço de vendas dos bens e serviços. Nesse cenário de feira, o cliente não fica restrito só à compra, mas pode ir para encontrar amigos, apreciar exposições de artes, apresentações musicais e participar de rodas de diálogos. 
Nesse sentido, as feiras colaborativas não fogem muito das tradicionais feiras livres existentes na cidade de Caruaru-PE, pois também são espaço de sociabilidade, com diversas ofertas, que fortalecem o senso de identidade local (MASCARENHAS; DOLZANI, 2008). A grande diferença dessas feiras estudadas é o seu foco na criatividade e posicionamento social dos produtos que são comercializados. Tais bens unem criatividade com técnicas, tecnologias e conhecimentos, por vezes aprendidos nas formações dos empreendedores (oriundos de cursos como Design, por exemplo), agregando valor por meio do ativo intelectual (CAIADO, 2008).

Nas entrevistas realizadas foi possível perceber dois tipos de feiras colaborativas que acontecem na cidade: aquelas independentes, organizadas pelas próprias marcas ou por coletivos da sociedade civil, e aquelas organizadas pela prefeitura. As diferenças entre essas feiras, apontadas pelas(os)entrevistadas(os), estão sintetizadas no Quadro 1.

\section{Quadro 1 - Feiras colaborativas independentes X Feiras colaborativas organizadas pela prefeitura}

\begin{tabular}{|c|c|c|}
\hline & $\begin{array}{l}\text { FEIRAS COLABORATIVAS } \\
\text { INDEPENDENTES }\end{array}$ & $\begin{array}{l}\text { FEIRAS COLABORATIVAS ORGANIZADAS } \\
\text { PELA PREFEITURA }\end{array}$ \\
\hline $\begin{array}{l}\text { Propósito da } \\
\text { feira }\end{array}$ & $\begin{array}{l}\text { Feiras com proposta de conscientização } \\
\text { social e realização de atividades } \\
\text { socioculturais, além do comércio dos } \\
\text { produtos. Discutem temas emergentes } \\
\text { através de oficinas e palestras. Focam o } \\
\text { posicionamento social das marcas. }\end{array}$ & $\begin{array}{l}\text { Visam a incentivar produtos locais, voltando- } \\
\text { se à comercialização dos produtos. }\end{array}$ \\
\hline Público & $\begin{array}{l}\text { É frequentada por um público que já } \\
\text { conhece a proposta dos coletivos ou do } \\
\text { evento. É um perfil de consumidor mais } \\
\text { consciente em incentivar a cultura local. }\end{array}$ & $\begin{array}{l}\text { É frequentada por vários perfis, que não } \\
\text { necessariamente conhecem as propostas } \\
\text { das marcas. Isso acontece porque a } \\
\text { prefeitura consegue investir mais em } \\
\text { divulgação e alcança mais pessoas. } \\
\text { Além disso, essas feiras são realizadas, } \\
\text { geralmente, em datas comemorativas da } \\
\text { cidade, quando aumenta o turismo local. }\end{array}$ \\
\hline Organização & $\begin{array}{l}\text { É organizada por um ou mais coletivos } \\
\text { e as marcas são convidadas a participar. } \\
\text { As marcas são responsáveis por levar } \\
\text { sua própria infraestrutura (mesas, } \\
\text { toldos, etc.) para expor seus produtos. }\end{array}$ & $\begin{array}{l}\text { É organizada pela prefeitura, podendo } \\
\text { contar com a ajuda de coletivos. A estrutura } \\
\text { é fornecida pela prefeitura para que as } \\
\text { marcas exponham seus produtos. Para } \\
\text { participar, as marcas precisam se inscrever e } \\
\text { aguardar a seleção, ou são convidadas pela } \\
\text { própria prefeitura. }\end{array}$ \\
\hline Divulgação & $\begin{array}{l}\text { É realizada boca a boca, ou via redes } \\
\text { sociais. }\end{array}$ & $\begin{array}{l}\text { É realizada por rádio, jornais locais, TV, } \\
\text { Internet. }\end{array}$ \\
\hline Local & Lugar público ou concedido por amigos. & $\begin{array}{l}\text { Lugar público onde estejam acontecendo } \\
\text { eventos comemorativos da cidade. }\end{array}$ \\
\hline $\begin{array}{l}\text { Taxa de } \\
\text { participação }\end{array}$ & $\begin{array}{l}\text { Os organizadores não cobram para as } \\
\text { marcas participarem da feira, e quando } \\
\text { o fazem, são valores simbólicos para a } \\
\text { manutenção do local. }\end{array}$ & $\begin{array}{l}\text { Paga-se uma taxa para o organizador da } \\
\text { feira, valor este que permite o fornecimento } \\
\text { da estrutura de stands, geradores de } \\
\text { energia, equipes de limpeza e segurança, } \\
\text { entre outros itens. }\end{array}$ \\
\hline
\end{tabular}

Fonte: Elaboração própria.

Como apresentado no Quadro 1, as principais diferenças existentes entre as feiras colaborativas independentes e aquelas organizadas pela prefeitura são o ente que realiza a organização, a forma como essa organização é feita em termos de infraestrutura, divulgação, convite aos participantes, etc., e o pagamento ou não de taxas. 
Vale também destacar as feiras colaborativas realizadas pela Universidade durante o evento de recepção para os novos alunos, com atividades voltadas também para os demais estudantes. O objetivo dessas feiras é mostrar as produções feitas pelos estudantes dos cursos, que utilizam ferramentas aprendidas na universidade, e constata-se maior participação dos estudantes do curso de Design. Desse modo, acredita-se que essa feira promovida pela universidade possui caráter formativo, diferenciando-se das outras duas expostas anteriormente.

A preocupação das feiras colaborativas independentes, organizadas pelas marcas ou pelos coletivos da sociedade civil, vai além do cunho comercial, como destacado pela entrevistada 3:

A gente vê o diferencial assim, essas feiras que a gente traz, traz muita cultura nelas, bandas, palestras, rodas de diálogos tem mesmo uma pauta assim, vamos falar sobre ocupação da estação, vamos falar sobre o dia da visibilidade da mulher lésbica, sabe? Traz pauta, e essas outras feiras [as feiras promovidas pela prefeitura] são mais voltadas para a feiras mesmo, para a venda, para o negócio, não é tão preocupada com a questão da cultura, a gente tem um diferencial que é a Flor \& Ser que traz essa questão de vender com a loja colaborativa que tá trazendo agora esse questão de ocupar a rua da Má Fama que é tão invisibilizada pela questão LGBT, então são assim vários aspectos (Entrevistada 3).

A ideia de movimentar a economia local junto a ações sociais, culturais e criativas torna-se a identidade das feiras independentes. As feiras promovidas pela prefeitura buscam a promoção do apoio local, mas com uma vertente mais comercial, conforme dito na entrevista anterior, enquanto as feiras independentes buscam explorar os posicionamentos sociais das marcas. A entrevistada 6 também comenta essa diferença entre as feiras:

A [marca] já participou de feira dos dois jeitos, já participou de evento organizados pela prefeitura e são muito diferentes de feiras organizadas por coletivo. As da prefeitura geralmente têm uma taxa pra pagar, não são altas, mas tem, e geralmente segue a estrutura tipo do São João [data festiva na cidade de Caruaru], teve barraquinhas que a gente pôde decorar do jeito que a gente quisesse, mas aí tinha a estrutura na Semana Santa também e eu percebo que mais voltado pra comércio e mercado mesmo as da prefeitura. Nas dos coletivos é mais o faça você mesmo, vamos contribuir do jeito que pode pra essa feira acontecer [...] e o conceito da marca é mais explorado nessa dos coletivos do que nas das prefeituras, é [como se] o simbolismo da marca importasse mais que a do comércio do que propriamente dito, apesar que também sejam voltadas para a comercialização, a feira tipo o coletivo do Cactos e a Fé Menina, elas têm o conceito, é o simbolismo mesmo muito maior de coletividade de união para o cenário artístico e cultural de Caruaru, que é pra Caruaru ir pra frente de novo (Entrevistada 6).

Além disso, os eventos organizados pela prefeitura alcançam um público mais diversificado do que aqueles feitos pelos coletivos. Como dito pela Entrevistada 1: "A feira do mercado criativo [organizada pela prefeitura] teve uma divulgação bem forte. A prefeitura divulgou bastante, e conseguiu atingir um público que as feirinhas colaborativas não conseguem atingir". 
Acredita-se que essas feiras têm sido uma saída positiva para os novos empreendedores nos tempos de crise, permitindo que os expositores saiam do ambiente virtual e tenham mais proximidade com o cliente, além da valorização da marca local. As feiras colaborativas dão a oportunidade de divulgar a marca e o produto, realizar novas parcerias e de aproximação física entre produtor(as) e cliente/consumidor(a). Desse modo, e segundo os(as) entrevistados(as), as feiras colaborativas são uma boa aliada para promover a economia criativa na cidade de Caruaru:

Ajuda muito porque tudo que gera renda aquece o comércio, tem muita gente que sobrevive do que faz na economia criativa mesmo, então isso já faz com que essa pessoa pague seus impostos, pague suas contas, pague sua alimentação, sua moradia, enfim. Muitas coisas que realmente ajudam, eu acredito que comprar do pequeno ajuda tanto a sociedade, principalmente se você pensar em uma sociedade local e isso faz com que a economia se desenvolva (Entrevistada 5).

As feiras colaborativas ajudam na divulgação dos produtos criativos e, querendo ou não, as feiras colaborativas geram a Economia Criativa porque são marcas que não querem só crescer, querem que a região cresça com ela, e Caruaru já é uma cidade de Economia Criativa, o alto do Moura, por exemplo, já uma Economia Criativa (Entrevistado 8).

Nas falas das(os) entrevistadas(os) foi possível observar que eles entendem a economia criativa como atividades artesanais ou qualquer outras que envolvam criatividade. O caráter coletivo, de inovação, saindo do convencional, de potencialização da realidade local, são elementos constantes nas suas falas.

Segundo Reis (2007), a Economia Criativa abrange todo o ambiente de negócios que existem em torno dos setores criativos. Ou seja, o produto criativo precisa gerar valor, produzir riqueza, assim, fazer um filme nas horas vagas com os amigos, ou confeccionar uma roupa para uso próprio, só irão fazer parte da Economia Criativa se gerarem renda, se alguém estiver lucrando diretamente com ela e para que o setor da Economia Criativa possa alavancar o desenvolvimento local precisa-se pensar na cadeia inteira (REIS, 2007). O produto artesanal pode ser classificado como Economia Criativa, mas a Economia Criativa não se restringe ao artesanato, pois esse é só uma das atividades enquadradas nos setores criativos.

Diante disso, percebe-se que a Economia Criativa possui potencial transformador no âmbito social, cultural, econômico e ambiental, como é possível observar no contexto caruaruense. Ao serem questionados(as) sobre como acreditam que a Economia Criativa pode ajudar no desenvolvimento da cidade de Caruaru-PE, os(as) entrevistados(as) mencionaram a geração de novos talentos, de novas possibilidades de produção e de consumo para aqueles(as) que não se identificam com a economia tradicional, e possibilidade de permanecer na região, dada a variedade de produtos e serviços criativos gerados, o que movimenta a economia local.

Também citaram a necessidade de empreender devido à crise econômica e à falta de empregos, o que, de certo modo, promove alguma inserção profissional (mesmo que temporária e precária) de pessoas em situação de desemprego, corroborando Vivant (2013), que afirma que trabalhar com criatividade é, muitas vezes, uma alternativa diante da precariedade contemporânea. É importante destacar que essa inserção acontece num cenário informal que pode ser caracterizado, de acordo com Locatelli, Benavides e 
Souza (2014, p. 11), como uma "Economia Criativa Informal", e que os(as) empreendedores(as) investigados(as) encontram-se, por vezes, em situação de vulnerabilidade, por não possuírem nenhum tipo de vínculo que lhes garanta direitos sociais.

Ademais, percebe-se ainda que, apesar de as feiras colaborativas serem uma forte expressão da Economia Criativa da cidade de Caruaru, promovendo-a em diferentes sentidos, elas mostram que a "classe criativa" nem sempre é bem paga, como entende Florida (2002), e que o ethos criativo nem sempre está associado à individualidade e meritocracia, tendo em vista que as feiras colaborativas mostram-se efetivas, no contexto analisado, quando realizadas coletivamente. Desse modo, percebemos a existência de possibilidades diferentes para as Economias Criativas, sendo importante analisá-las a partir do contexto no qual elas se inserem, e das particularidades históricas, culturais e sociais que carregam.

\section{REFLEXÕES FINAIS}

Este trabalho buscou realizar análise das feiras colaborativas que compõem a Economia Criativa no município de Caruaru, Pernambuco. A partir deste estudo pode-se destacar três fatores importantes. O primeiro refere-se ao perfil dos(as) participantes das feiras colaborativas, que são jovens adultos entre 19 e 33 anos de idade, com protagonismo feminino. São também estudantes universitários ou recém-formados(as) que buscam se inserir no mercado de trabalho, dado o contexto de crise econômica e desemprego, e promover a economia local. Estes agentes atuam em diversos segmentos, todos inseridos do setor de criações funcionais, um dos quatro setores criativos que compõem a chamada Economia Criativa, de acordo com a Unctad. Além disso, os empreendimentos possuem posicionamentos sociais claros, ligados à sustentabilidade e empoderamento feminino.

O segundo fator importante refere-se à caracterização das feiras colaborativas que se revelaram um importante canal de divulgação e promoção para essa geração de jovens empreendedores(as). Trata-se de uma maneira de expor e divulgar os produtos a custos reduzidos, além de promover discussões sobre questões sociais importantes, conscientizando o público participante dessas feiras, por meio de oficinas, palestras e apresentações artísticas. Esse caráter formativo das feiras aparece principalmente nas feiras colaborativas independentes, organizadas pelas próprias marcas ou por coletivos da sociedade civil que, em certa medida, se diferenciam das feiras colaborativas promovidas pela prefeitura, conforme referido nas entrevistas. Estas últimas parecem estar mais voltadas à comercialização dos produtos, além de cobrar taxas aos participantes, e de atingir um público de visitantes maior, dada a maior divulgação, geralmente atrelada aos festejos da cidade.

O terceiro fator diz respeito ao fato de que o processo produtivo dessas marcas é feito pelos(as) próprios(as) empreendedores(as), muitas vezes em suas casas, o que os aproxima das produções de confecções realizadas nos negócios locais (PEREIRA, 2011; SÁ, 2018a). A principal forma de distribuição dos produtos é feita via Internet, nas feiras colaborativas e na loja colaborativa da cidade, e o público consumidor destes produtos são em sua maioria mulheres, "pessoas alternativas", preocupadas com o apoio à produção local, tendo o consumo um "caráter extrapreço" (LOCATELLI; BENAVIDES; SOUZA, 2014). 
Conclui-se, portanto, que as feiras colaborativas são importantes para o desenvolvimento da Economia Criativa de Caruaru-PE, por possibilitarem a geração de renda mediante, principalmente, a distribuição e potencialização do consumo de produtos e serviços criativos. Afinal, é por meio das feiras colaborativas que os(as) pequenos(as) produtores(as) expõem, divulgam e vendem suas produções. Também é nas feiras que eles(as) formam parcerias e se aproximam fisicamente de seus clientes/consumidores. Tais características aproximam as feiras colaborativas das feiras tradicionais da cidade, diferenciando-se somente o tipo de produto e as ferramentas tecnológicas utilizadas, principalmente na sua distribuição.

Desse modo, destaca-se a importância de compreender a dinâmica da Economia Criativa a partir das especificidades do contexto no qual ela acontece, pois, no caso de Caruaru-PE, a Economia Criativa, impulsionada, em parte, pelas feiras colaborativas, possui características particulares da dinâmica produtiva existente nessa cidade, como o caráter informal dos negócios, as produções realizadas de modo artesanal e caseiro e as trocas culturais e simbólicas, bem como o caráter formativo existentes nas feiras. Ademais, cabe aqui uma ressalva: apesar do discurso de glamourização - usando termo de Vieira e Antunes (2018) ao se referirem à economia colaborativa - da Economia Criativa, esta pode servir como forma de mascarar estratégias neoliberais e tornar-se, muitas vezes, alternativa à precariedade (VIVANT, 2013). Desse modo, não se pode deixar de negar a situação de vulnerabilidade social em que muitos dos seus profissionais se encontram, uma vez que assumem todas as responsabilidades/dificuldades de seus pequenos negócios, tão importantes para a economia local, sem muitos incentivos, principalmente no que se refere aos seus direitos sociais, como já discutido por Sanguinet, Calvete e Waismann (2016).

A principal limitação encontrada para a realização deste trabalho foi o fato de as feiras colaborativas ainda serem pouco discutidas no meio acadêmico, sendo escasso o material bibliográfico sobre o tema. Devido a isso, sugere-se mais pesquisas sobre as feiras colaborativas e a Economia Criativa na cidade de Caruaru e região, analisando principalmente o empreendedorismo feminino; os novos meios de vendas e controle do público consumidor por meio das redes sociais; a importância da primeira loja colaborativa da cidade e região como apoio à Economia Criativa, bem como uma análise crítica sobre as condições de trabalho dos(as) empreendedores(as) dessa economia.

\section{REFERÊNCIAS}

ALMEIDA, S. P. N. C. Fazendo a feira: estudo das artes de dizer, nutrir e fazer etnomatemático de feirantes e fregueses da Feira Livre do Bairro Major Prates em Montes Claros. Montes Claros, MG. 2009. Dissertação (Mestrado) - Universidade de Montes Claros, Montes Claros, MG, 2009.

ALMEIDA PEREIRA, A. M. B. Dinâmica formal-informal em lavanderias de jeans e suas implicações nas relações de trabalho. 2018. Tese (Doutorado) - Universidade Federal da Paraíba, João Pessoa, PB, 2018.

BARDIN, L. Análise de conteúdo. São Paulo: Edições 70, 2011.

BARROS, A. J. S.; SOUZA, N. A. Fundamentos de metodologia científica. 3. ed. São Paulo, SP: Pearson Prentice Hall, 2007.

CAIADO, A. S. C. Algumas considerações sobre a Economia Criativa. In: ENCONTRO DE ESTUDOS MULTIDISCIPLINARES EM CULTURA (ENECULT), 4., 2008, Salvador. Anais [...]. Salvador, BA, Brasil: Ufba, 2008.

DORIA, C. A. Vantagens da análise de modelos de negócio na economia da cultura brasileira. Revista Observatório Itaú Cultural/OIC, São Paulo, SP, n. 3, p. 74-85, 2007. 
ERIG, G. A.; MELO, S. M. C. Feira livre como um atrativo cultural: o caso da Feira do Bosque em Palmas - TO. In: FÓRUM INTERNACIONAL DE TURISMO DO IGUASSU, 9., 2015, Foz do Iguaçu. Anais [...]. Foz do Iguaçu, Brasil, 2015.

FIRJAN. Federação das Indústrias do Rio de Janeiro. Mapeamento da indústria criativa no Brasil. 2016. Disponível em: http://www.firjan.com.br/economiacriativa/download/mapeamento-industria-criativa2014.pdf. Acesso em: 22 maio 2017.

FLICK, U. Introdução à pesquisa qualitativa. 3. ed. Porto Alegre: Artmed. 2009.

FLORIDA, R. The Rise of the Creative Class. New York: Basic Books, 2002.

GERHARDT, T. E.; SILVEIRA, D. T. Métodos de pesquisa. Porto Alegre: Editora da UFRGS, 2009.

GIL, A. C. Como elaborar projetos de pesquisa. 5. ed. São Paulo, SP: Atlas. 2016.

HOWKINS, J. Ecologias criativas. In: REIS, A. C. F.; KAGEYAMA, P. Cidades criativas - perspectivas. São Paulo: Garimpo de Soluções, 2011.

IBGE. Instituto Brasileiro de Geografia e Estatística. Disponível em: https://cidades.ibge.gov.br/brasil/pe/ caruaru/panorama. Acesso em: 13 jun. 2019.

IPHAN. Instituto do Patrimônio Histórico e Artístico Nacional. Dossiê IPHAN 9. Feira de Caruaru. Brasília, DF: IPHAN; Ministério da Cultura, 2006.

LANDRY, C. The creative city: a toolkit for urban innovators. 2. ed. London, UK: Earthscan, 2008.

LIRA, S. M. Muito além das Feiras da Sulanca: a produção da confecção no Agreste/PE. Recife: Ed. Universitária da UFPE, 2011.

LOCATELLI, L. E.; BENAVIDES, Z. A. C.; SOUZA, T. C. Economia criativa e consumo alternativo em feiras de artesanato no Município de Ilhéus, Bahia. In: SEMANA DO ECONOMISTA, 4., ENCONTRO DE EGRESSOS, 4., 2014, Ilhéus. Anais [...]. Ilhéus, Brasil: Universidade Estadual de Santa Cruz, 2014.

MASCARENHAS, G.; DOLZANI, M. C. S. Feira livre: territorialidade popular e cultura na metrópole contemporânea. Ateliê Geográfico, Goiás, v. 2, n. 2, p. 72-87, 2008.

MIGUEZ, P. Economia criativa: uma discussão preliminar. In: NUSSBAUMER, M. G. (org.). Teorias \& políticas da cultura: visões multidisciplinares. Salvador: Editora da Ufba, 2007. p. 95-113.

MINISTÉRIO DA CULTURA. Plano da Secretaria da Economia Criativa: políticas, diretrizes e ações, 20112014. Brasília, Ministério da Cultura, 2011.

NAÇÕES UNIDAS. Relatório de economia criativa 2010: economia criativa, uma opção de desenvolvimento viável. Brasília: Secretaria da Economia Criativa; Minc; São Paulo: Itaú Cultural, 2012. Disponível em: http://unctad.org/pt/docs/ditctab20103_pt.pdf. Acesso em: 19 abr. 2019.

NEWBIGIN, J. A economia criativa: um guia introdutório. Reino Unido: Britsh Council, 2010.

PACHECO, A. P. C.; BENINI, E. G. A Economia criativa em época de crise: o desenvolvimento endógeno brasileiro na obra de Celso Furtado. Brazilian Journal of Political Economy, São Paulo, SP, v. 38, n. 2, p. 324-337, 2018.

PEREIRA, E. Qualificação profissional e relações de trabalho no pólo de confecções de Pernambuco: trajetória e perspectivas de atuação do Senai. 2011. Dissertação (Mestrado) - Universidade Federal de Campina Grande, Campina Grande, PB, 2011.

RAIS. Relação Anual de Informações Sociais. Brasília. Disponível em: http://pdet.mte.gov.br/. Acesso em: 13 jun. 2019.

REIS, A. C. F. Economia criativa como estratégia de desenvolvimento: uma visão dos países em desenvolvimento. São Paulo, SP: Itaú Cultural, 2008.

REIS, A. C. F. Economia da cultura e desenvolvimento sustentável: o caleidoscópio da cultura. Barueri, SP: Manole, 2007.

SÁ, M. Filhos das feiras: uma composição do campo de negócios do agreste. Recife: Fundação Joaquim Nabuco; Editora Massangana, 2018a.

SÁ, M. Novas e velhas distinções na comunidade artesã do Alto do Moura: tensões emergentes entre membros-proprietários(as) de negócios no século 21. In: CONGRESSO BRASILEIRO DE ESTUDOS ORGANIZACIONAIS (CBEO), 5., 2018. Curitiba. Anais [...]. Curitiba, Paraná: SBEO, 2018b.

SANGUINET, E. R.; CALVETE, C. S.; WAISMANN, A. P. Economia da cultura e economia criativa no Brasil: uma análise conjuntural do mercado de trabalho (2014-2016). In: VALIATI, L.; MOLLER, G. (org.). Economia criativa, cultura e políticas públicas. Porto Alegre: Editora da UFRGS; Cegov, 2016. P. 279-299.

SANTOS, E.; HELAL, D. H. Práticas de trabalho da cultura popular no agreste de Pernambuco: entre o moderno e o tradicional. Revista Eletrônica de Ciência Administrativa, v. 16, n. 2, p. 127-150, 2017.

SANTOS, E.; HELAL, D. H. O moderno e o tradicional no agreste de Pernambuco. Revista Ciência e Trópico, v. 42, n. 1, p. 163-188, 2018. 
SOUZA. C. R. As feiras livres como lugares de produção cotidiana de saberes do trabalho e educação popular nas cidades: alguns horizontes teóricos e analíticos no campo trabalho-educação. Trabalho Necessário, Niterói, RJ, v. 13, n. 22, p. 126-144, 2015.

TOLILA, P. Cultura e economia: problemas, hipóteses, pistas. São Paulo: Iluminuras; Itaú Cultural, 2007.

TRIVIÑOS, A. N. S. Introdução à pesquisa em ciências sociais: a pesquisa qualitativa em educação. São Paulo: Atlas, 1987.

VALIATTI, L. Economia da cultura: uma revisão teórica. Revista Observatório Itaú Cultural, São Paulo, SP, n. 23, p. 19-27, 2017.

VIEIRA, C. R. S.; ANTUNES, E. D. D. O trabalho nas economias colaborativas: a precarização e o discurso da glamourização. In: CONGRESSO BRASILEIRO DE ESTUDOS ORGANIZACIONAIS (CBEO), 5., 2018. Curitiba. Anais [...]. Curitiba, Brasil: SBEO, 2018.

VIVANT, E. Creatives in the city: Urban contradictions of the creative city. City, Culture and Society, v. 4, n. 2, p. 57-63, 2013.

YÚDICE, G. A conveniência da cultura: usos da cultura na era global. Belo Horizonte: Editora UFMG, 2006. 